\title{
Novel green synthesis of gold nanoparticles using Citrullus lanatus rind and investigation of proteasome inhibitory activity, antibacterial, and antioxidant potential
}

\author{
This article was published in the following Dove Press journal: \\ International Journal of Nanomedicine \\ 2 December 2015 \\ Number of times this article has been viewed
}

\section{Jayanta Kumar Patra Kwang-Hyun Baek}

School of Biotechnology, Yeungnam University, Gyeongsan, Gyeongbuk, Republic of Korea
Correspondence: Kwang-Hyun Baek School of Biotechnology, Yeungnam University, Gyeongsan, Gyeongbuk 7|2-749, Republic of Korea

$\mathrm{Tel}+82538103029$

Fax +82538104769

Email khbaek@ynu.ac.kr
Abstract: Biological synthesis of nanoparticles using nontoxic, eco-friendly approaches is gaining importance owing to their fascinating biocompatibility and environmentally benign nature. This study describes the green synthesis approach for synthesis of gold nanoparticles (ANPs) using aqueous extract of the rind of watermelon as a fruit waste and evaluate its biopotential in terms of proteasome inhibitory activity, antibacterial, and antioxidant potential. The synthesized ANPs were characterized using UV-vis spectroscopy, scanning electron microscopy, $\mathrm{X}$-ray diffraction, Fourier-transform infrared spectroscopy, and thermogravimetric analysis. The surface plasmon resonance spectra of ANPs were obtained at $560 \mathrm{~nm}$. Scanning electron microscopy image revealed that particles had a spherical shape and have a size distribution of 20-140 nm, followed by the elemental analysis by energy-dispersive X-ray spectroscopy. X-ray diffraction analysis confirmed the crystallite nature of the ANPs and Fourier-transform infrared spectroscopy revealed the involvement of bioactive compounds from watermelon rind in the synthesis, capping, and stabilization of ANPs. ANPs exhibited potential antibacterial activity against five different foodborne pathogenic bacteria with diameter of inhibition zones ranged between 9.23 and $11.58 \mathrm{~mm}$. They also displayed strong synergistic antibacterial activity together with kanamycin (11.93-21.08 mm inhibition zones) and rifampicin (10.32-24.84 mm inhibition zones). ANPs displayed strong antioxidant activity in terms of DPPH radical scavenging (24.69\%), nitric oxide scavenging (25.62\%), ABTS scavenging (29.42\%), and reducing power. Significantly high proteasome inhibitory potential of the ANPs $(28.16 \%)$ could be highly useful for cancer treatment and targeted cancer drug delivery. Overall, results highlight a potential lowcost green method of synthesizing ANPs from food waste materials. Significant biopotentials of synthesized ANPs could make it a potential candidate for its application in the biomedical, pharmaceutical, cosmetics, and food sectors.

Keywords: antibacterial, antioxidant, gold nanoparticles, proteasome inhibitor, watermelon peel, green synthesis, biosynthesis

\section{Introduction}

Some natural compounds have the ability to reduce metal ions into metal nanoparticles. ${ }^{1}$ However, the shape, size, and morphology of nanoparticles play important roles in controlling their physical and chemical properties. ${ }^{2,3}$ These unique, interesting physical, chemical, and biological properties of the nano-ranged materials have attracted the present scientific world for their potential applications in different biomedical, electrical, and applied sciences. ${ }^{4}$ Chemical reduction methods are usually used for the synthesis of high amounts of metal nanoparticles on an industrial scale, however, 
they are more expensive, hazardous to the environment, and require consumption of high levels of energy. ${ }^{3,5}$ Synthesis of nanoparticles using various noble metals has the potential for use in a wide range of biomedical applications such as antibacterial agents, cancer treatments, DNA analysis, drug carriers for targeted delivery, gene therapy, magnetic resonance imaging, and molecular imaging, as well as in biosensors, catalysis, and separation science owing to their unique physical and chemical properties. ${ }^{6,7}$ Metal nanoparticles are widely applied in the biomedical and pharmaceutical fields; therefore, there is an increasing demand for their production using eco-friendly and nontoxic approaches that are more stable during large-scale production and applications. ${ }^{3,5}$ Biological synthesis of nanoparticles using green technology has been receiving increased attention owing to their eco-friendly and nontoxic nature. ${ }^{8}$ Biological synthesis of nanoparticles using plant extracts, plant products, bacteria, yeast, and fungi has been suggested as a valuable alternative tool toward traditional chemical synthesis methods. ${ }^{9-12}$

Recently, synthesis of gold nanoparticles (ANPs) has been the focus of intense scientific research owing to their fascinating chemical, electronic, and optical properties and potential applications in biomedicine, sensing, and catalysis. ${ }^{13,14}$ The ANPs are a promising candidate for biomedical engineering and drug delivery applications owing to their unique dimensions, nontoxicity, surface functionalities, and capacity for controlled drug release. ${ }^{15}$ Moreover, these nanoparticles can effectively overcome all the physiological barriers and transport the drug to specific target areas such as intracellular compartments or specific cells via passive or ligand-mediated targeting approaches. ${ }^{16}$

One of the important tasks for synthesis of ANP, however, is the development of a simple environmentally benign method for preparation of ANPs using biological sources. ${ }^{17,18}$ Conventional synthetic methods for the synthesis of ANPs using chemicals such as sodium citrate, sodium borohydride, and organic solvents have raised concerns regarding their health hazards and environmental toxicity. ${ }^{17,18}$ Green technology methods for the synthesis of biogenic ANPs are eco-friendly, nontoxic, and cost-effective with unique properties and applications in the biological tagging, biomedical, and pharmaceutical fields. ${ }^{19}$ Recently, agricultural wastes such as banana peels ${ }^{20}$ and custard apple peels, ${ }^{21}$ which are rich in phenolic compounds, pectin, and lignin, have been investigated for their potential for synthesis of different nanoparticles. However, additional studies investigating the potential use of other fruit peel extracts from food and agricultural biowastes as surfactants/reductants for the synthesis of different types of nanoparticles still need to be fully explored.

In general, the emergence of different types of infectious diseases caused by different pathogenic and antibioticresistant bacteria poses a serious threat to the public health worldwide. Over the years, the intensive use of antibiotics to control infections has resulted in the development of antibiotic-resistant pathogens. ${ }^{22}$ Considering the unique properties of various nanoparticles, they have been utilized in medical practices and biomedical research. ${ }^{22}$ Furthermore, the nanoparticles affect the pathogenic bacteria by causing toxicity in the bacterial cell, however, they do not affect the normal cells and hence such particles are safe to use in drug formulation. $^{22}$

The proteasomes are large multicatalytic proteinase complexes located in the cytoplasm and nucleus of all the eukaryotic cells. ${ }^{23}$ The ubiquitin-proteasome system plays an essential regulatory role such as cell cycle progression, proliferation, differentiation, angiogenesis, and apoptosis in the cellular processes. The alteration of proteasomal activity contributes immensely to the pathological states of several clinical disorders such as inflammation, neurodegeneration, and cancer. Human cancer cells possess an elevated level of proteasome activity; therefore, inhibition of the proteasome activity could be a novel approach for treatment of cancer. $^{23-25}$

Watermelon (Citrullus lanatus) is an abundantly available fruit that is widely consumed worldwide. ${ }^{8}$ The fruit is edible and used for making juices and salads; however, the rind is discarded and currently considered a waste product with no commercial value. Watermelon outer peel (WMP) consists of various components, including cellulose, citrulline, pectin, proteins, and carotenoids, ${ }^{26,27}$ therefore, it is abundant in a variety of functional groups, including carboxylic (pectin) and hydroxyl (cellulose) compounds. ${ }^{8}$ Additionally, various components in watermelon have been reported to have antioxidant capacity and bioactivity. ${ }^{28-30}$

In this study, we attempted to synthesize colloidal ANPs using the aqueous extract of WMP and to evaluate the biopotentials of ANPs in terms of its proteasome inhibitory activity, antibacterial, and antioxidant potential.

\section{Materials and methods}

\section{Preparation of aqueous extract of the rind of watermelon}

The rind of watermelon (C. lanatus var. lanatus) purchased from a local supermarket at Gyeongsan was collected after completely removing the edible portion of the fruit, then 
washed twice with double distilled water. Next, the rind was cut into small pieces $(\sim 10 \mathrm{~mm})$ with a knife, divided into $40 \mathrm{~g}$ aliquots, and immersed in $200 \mathrm{~mL}$ of deionized water in a $500 \mathrm{~mL}$ conical flask. The mixture was subsequently boiled for 10 minutes with continuous stirring using a magnetic stirrer, after which the watermelon aqueous extract (WAQ) was cooled, filtered through Whatman no 1 filter paper, collected into a sterilized bottle, and kept at $4^{\circ} \mathrm{C}$ until further use.

\section{Green synthesis of ANPs using WAQ}

The ANPs were prepared by suspending $10 \mathrm{~mL}$ of WAQ in $100 \mathrm{~mL}$ of $1 \mathrm{mM}$ auric chloride $\left(\mathrm{AuCl}_{3}\right.$, Sigma-Aldrich Co., St Louis, MO, USA) with continuous stirring in a $500 \mathrm{~mL}$ conical flask at room temperature. ${ }^{31}$ The reduction of $\mathrm{AuCl}_{3}$ to ANPs occurred rapidly and resulted in a change in the color of the solution from colorless to dark brown after 1 hour of incubation. The ANPs solution was then centrifuged at 10,000 rpm for 30 minutes in a high-speed centrifuge (Supra 22K, Hanil Science Industrial CO., Ltd, Daejeon-Dong, Gangneung-Si, Korea), after which the pellets were washed twice with distilled water and dried to powders using a vacuum dryer (LVS 201T, ILMVAC GmbH, Ilmenau, Germany).

\section{Characterization of synthesized ANPs}

The synthesized ANPs were characterized by various analytical measurements, including UV-vis spectroscopy, Fourier-transform infrared spectroscopy (FT-IR), thermogravimetric analysis (TGA), scanning electron microscopy (SEM), energy-dispersive X-ray (EDX) analysis, and X-ray powder diffraction (XRD) analysis. ${ }^{5,31}$

The reduction of $\mathrm{Au}$ ions in the reaction medium was monitored by measuring the absorption spectra of the colloidal solution at a resolution of $1 \mathrm{~nm}$ between 350 and $750 \mathrm{~nm}$ using a microplate reader (Infinite 200 PRO NanoQuant, Tecan, Männedorf, Switzerland). FT-IR analysis of the synthesized powdered ANPs was conducted using an FT-IR spectrophotometer (Jasco 5300, Jasco, Mary’s Court, Easton, MD, USA) in the wavelength range of $400-4,000 \mathrm{~cm}^{-1}$. The sample was blended with potassium bromide in a 1:100 ratio, then compressed to a $2 \mathrm{~mm}$ semitransparent disc, after which the various modes of vibrations were analyzed for the presence of different types of functional groups in ANPs and WAQ. The morphology of the ANPs was analyzed using an SEM. The powdered ANPs were uniformly spread and sputter coated with platinum in an ion coater for 120 seconds, then observed by SEM (S-4200, Hitachi Ltd., Tokyo, Japan). The size distribution of the nanoparticle was obtained by counting 150 particles from an enlarged SEM image. ${ }^{32}$
Elemental analysis of the powdered ANPs was conducted using an EDX detector (EDS, EDAX Inc., Mahwah, NJ, USA) attached to the SEM machine. TGA analysis of the powdered ANPs was performed on a TGA machine (SDT Q600, TA Instruments, New Castle, DE, USA). For TGA analysis, ANPs were placed in an alumina pan and heated from $20^{\circ} \mathrm{C}$ to $700^{\circ} \mathrm{C}$ at a ramping time of $10^{\circ} \mathrm{C} /$ minute. The crystalline structure of the powdered ANPs was determined using an XRD machine (X'Pert MRD model, PANalytical, Almelo, the Netherlands). The machine setup was $30 \mathrm{kV}, 40$ $\mathrm{mA}$ with $\mathrm{Cu}-\mathrm{K} \alpha$ radians at an angle of $2 \theta$.

\section{Proteasome inhibitory activity}

The proteasome inhibitory potential of ANPs was assayed using a 20S proteasome assay kit for drug discovery (ENZO Life Sciences, Farmingdale, NY, USA) according to the manufacturer's protocol. ANP at 10 and $100 \mu \mathrm{g} / \mathrm{mL}$, and standard reference compound, epoxomicin at 0.56 and $5.56 \mu \mathrm{g} / \mathrm{mL}$ were used for the assay. Suc-LLVY-AMC (ENZO Life Sciences, Farmingdale, NY, USA) (37.5 mM) was used as substrate to estimate the Chymotrypsin-like proteasomal activity of the ANPs in a 96-well microplate. The fluorescence intensities were measured at an excitation of $350 \mathrm{~nm}$ and emission of $440 \mathrm{~nm}$ at $30^{\circ} \mathrm{C}$ reaction temperature using the microplate reader.

\section{Antibacterial activity}

The antibacterial potential of ANPs was determined by the standard disc diffusion method. ${ }^{33}$ Five different foodborne bacteria were used in the study: Bacillus cereus ATCC 13061, Listeria monocytogenes ATCC 19115, Staphylococcus aureus ATCC 49444, Escherichia coli ATCC 43890, and Salmonella typhimurium ATCC 43174. All pathogens were obtained from the American Type Culture Collection (ATCC, Manassas, VA, USA). The bacterial pathogens were maintained on nutrient agar media (Difco, Becton, Dickinson and Company, Sparks Glencoe, MD, USA) at $4^{\circ} \mathrm{C}$ until further analysis. Prior to use, powder of ANPs was dissolved in 5\% dimethyl sulfoxide (DMSO, 1,000 $\mu \mathrm{g} / \mathrm{mL}$ ) and sonicated at $30^{\circ} \mathrm{C}$ for 15 minutes to prepare a colloidal solution, from which a $50 \mu \mathrm{g} / \mathrm{disc}$ was used for the assay. Kanamycin and rifampicin at $5 \mu \mathrm{g} /$ disc were taken as positive controls, whereas 5\% DMSO was used as the negative control. The diameter of zones of inhibition was measured after 24 hours of incubation at $37^{\circ} \mathrm{C}$. The minimum inhibitory concentration (MIC) and minimum bactericidal concentration (MBC) were determined by the twofold dilution method, with minor modifications. ${ }^{34}$ 
To investigate the synergistic effects of ANPs, different concentrations of ANPs $(1 \mathrm{mg} / \mathrm{mL})$ and two standard antibiotics (kanamycin and rifampicin at $200 \mu \mathrm{g} / \mathrm{mL}$ ) were mixed at a $1: 1$ ratio and sonicated for 15 minutes at room temperature. A total of $50 \mu \mathrm{L}$ of the ANP-antibiotics mixture containing $25 \mu \mathrm{g}$ ANPs and $5 \mu \mathrm{g}$ antibiotics were used for determination of the antibacterial activity by the disc diffusion method. ${ }^{35}$

\section{Antioxidant activity}

The antioxidant potential of the ANPs was determined by several assay methods, including DPPH free radical scavenging, nitric oxide scavenging, ABTS free radical scavenging, and reducing power assay. ANPs and butylated hydroxyl toluene (BHT, Supelco, Bellefonte, PA, USA) were used as the standard reference compound at $20-100 \mu \mathrm{g} / \mathrm{mL}$ for all assays. The WAQ extract was taken as control for all the antioxidant assays.

The DPPH free radical scavenging potential of ANPs was determined by the standard procedure. ${ }^{36}$ The absorbance of the reaction mixtures was recorded at $517 \mathrm{~nm}$ using a microplate reader, and the results were interpreted according to the following equation:

$$
\% \text { scavenging }=\frac{A_{\mathrm{c}}-A_{\mathrm{t}}}{A_{\mathrm{c}}} \times 100 \%
$$

where $A_{\mathrm{c}}$ is the absorbance of the control and $A_{\mathrm{t}}$ is the absorbance of the treatment.

The nitric oxide radical scavenging potential of ANPs was determined according to Equation 1 by the standard method. ${ }^{37}$ The ABTS radical scavenging activity of ANPs was measured according to Equation 1 as per the standard method. ${ }^{38}$ The reducing power of ANPs was determined in terms of absorbance at $700 \mathrm{~nm}$ by the standard method. ${ }^{39}$

\section{Statistical analysis}

All data are presented as the mean \pm standard deviation. Statistical analysis using ANOVA followed by Duncan's test at $P<0.05$ was conducted using the Statistical Analysis Software (SAS, version 9.4, SAS Institute Inc., Cary, NC, USA).

\section{Results and discussion Synthesis of ANPs}

The WMP, which consists of various components, including cellulose, pectin, proteins, and carotenoids with both carboxylic and hydroxyl groups, is suitable for extracellular synthesis of colloidal ANPs from $\mathrm{AuCl}_{3}$ aqueous solution. ${ }^{8}$ Complete reduction of the gold ions was observed after
6 hours of incubation at room temperature. The change in color of the reaction mixture was observed from 1 hour of incubation, and the solution was dark purple at 6 hours to complete dark at 24 hours, confirming the synthesis of colloidal ANPs in the reaction medium (Figure 1, inset). The color exhibited by the metallic colloidal nanoparticles was due to the coherent excitation of all free electrons within the conduction band that led to the in-phase oscillation (ie, surface plasmon resonance [SPR]). ${ }^{40}$ The bioactive compounds present in the WAQ might have provided reducing and stabilizing agents to the metallic gold ions in the solution to convert them to ANPs. ${ }^{8}$

\section{Characterization of ANPs}

The UV-vis spectroscopy is one of the most common techniques for authentication of the formation and stability of ANPs in the aqueous solution. ANPs have been reported to exhibit a dark purple color in aqueous solution that is related to their intensity and size owing to its SPR. ${ }^{41,42}$ The UV-vis spectra of the synthesized colloidal ANPs recorded at different time intervals are presented in Figure 1. The absorbance peaks indexed as A, B, C, D, E, F, G, and $\mathrm{H}$ correspond to $\mathrm{AuCl}_{3}$ and the reduction of $\mathrm{AuCl}_{3}$ by WAQ with different time intervals (0 minute, 30 minutes, 1, 3, 6, 12, and 24 hours) at room

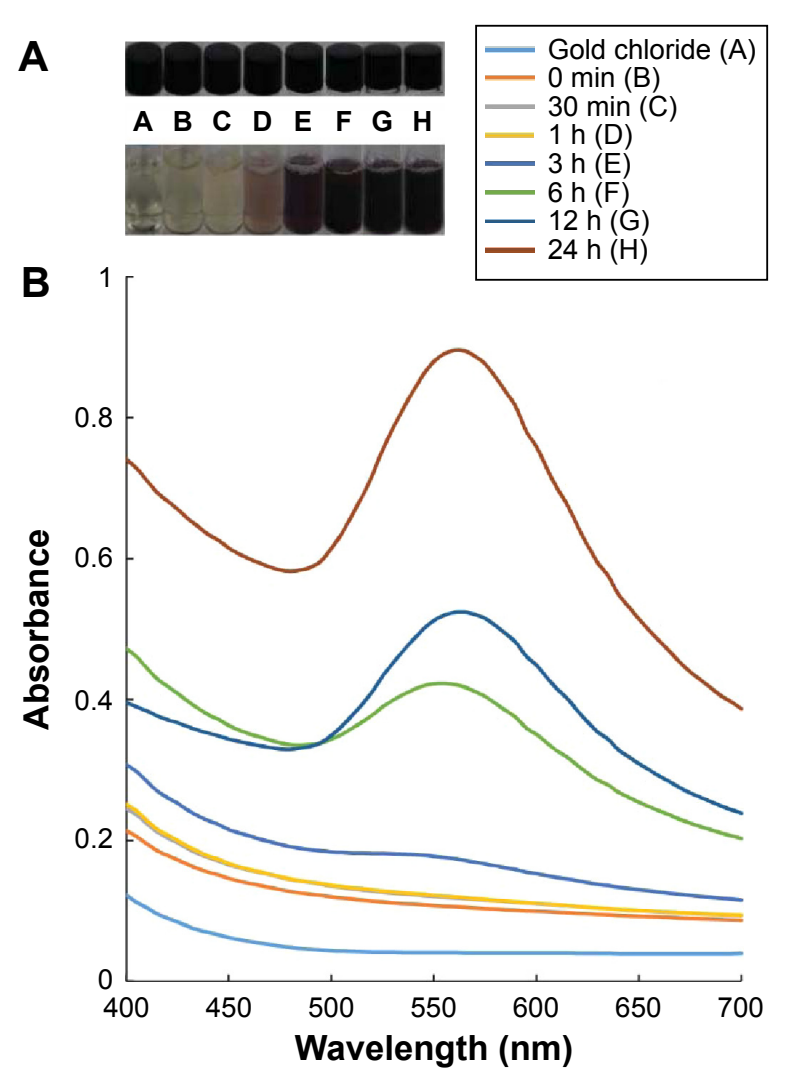

Figure I (A,B) UV-vis spectra of gold nanoparticles synthesized using the aqueous extract of watermelon rind.

Note: (A) Change in color of the solution with respect to incubation time. Abbreviations: UV-vis, ultraviolet-visible; min, minutes; h, hours. 
temperature (Figure 1). Spectral analysis revealed that the SPR absorption maxima peak of ANPs occurred at $560 \mathrm{~nm}$ with a high absorbance value, which is specific for ANPs. ${ }^{41}$ The UV-vis spectra were further recorded after 24 hours, but the intensity of the color did not intensify after 24 hours, confirming that the reaction was completed within 24 hours.

The WAQ and powdered ANPs were analyzed by FT-IR to predict the role of reducing and stabilizing capacity of WMP (Figure 2). The FT-IR analysis of ANPs and WAQ was performed in the range of $400-4,000 \mathrm{~cm}^{-1}$. The FT-IR signals of WAQ and aqueous WMP extract were observed at 3,438, $2,353,2,167,1,645,1,087$, and $564 \mathrm{~cm}^{-1}$. The FT-IR signals of ANPs were observed at 3,548, 3,464, 2,367, 1,654, 1,106, and $526 \mathrm{~cm}^{-1}$. The peak band at $3,438 \mathrm{~cm}^{-1}$ was responsible for the $\mathrm{OH}$-stretching vibration in WAQ, ${ }^{43}$ which might have shifted to $3,464 \mathrm{~cm}^{-1}$ in ANPs. These vibrations correspond to the hydroxyl functional group in alcohols and phenolic compounds. ${ }^{44,45}$ The band at $1,645 \mathrm{~cm}^{-1}$ in WAQ was due to the presence of carbonyl amide I vibrations, and this band was shifted to $1,654 \mathrm{~cm}^{-1}$ in ANPs because of the proteins/ peptides and amino acids present in the WAQ extract that possibly had been involved in the capping and reduction of $\mathrm{Au}$ ions to ANPs through the amine groups. ${ }^{3,5}$ The bands at 1,106 and $1,087 \mathrm{~cm}^{-1}$ may be assigned to the stretching vibration of $\mathrm{C}-\mathrm{O}$ of $1^{\circ}$ and $2^{\circ}$ alcohols. ${ }^{31}$ The band at $564 \mathrm{~cm}^{-1}$ may be assigned to alkyl halide groups, which are shifted to $526 \mathrm{~cm}^{-1}$ in the case of ANPs. ${ }^{46}$ The shifting of different functional groups in the case of ANPs from the WAQ stretch showed the progress of reduction of ANPs. ${ }^{31}$ Watermelon rind is rich in phenolic compounds, flavonoids, and lycopene. ${ }^{47-50}$ It contains $2-20 \mathrm{mg} / \mathrm{g}$ dry weight of the amino acid citrulline ${ }^{51,52}$ which is a major compound (nonessential amino acid) present in the watermelon rind which might have been responsible for the reduction and capping of the synthesized ANPs in this study. ${ }^{53}$

The morphology and structure of the synthesized powdered ANPs were observed under SEM (Figure 3). SEM analysis confirmed that the metal particles were in a nano-size with spherical, triangular, and cuboidal shapes (Figure 3A and B). The SEM image was taken after 1 month of the synthesis after completion of all reactions, and the particles did not agglomerate which showed that the nanoparticles are stable (Figure 3B). The shape of ANPs was mostly spherical. The particle size distribution of the ANPs was obtained by counting 150 particles from an enlarged SEM image and it was found out in the range of 20-140 nm (Figure 3C). These findings indicate that WAQ might have acted as both a reducing and stabilizing agent in synthesizing ANPs. EDX quantitative analysis confirmed that the elemental composition of the synthesized particle was primarily gold with the highest elementary composition, whereas oxygen, chlorine, and potassium are in traces (Figure 3D).

The crystallite nature of the ANPs was confirmed by XRD analysis. Figure 4 shows the representative XRD pattern of the lyophilized nanoparticles synthesized by the aqueous extract of WMP after complete reduction of $\mathrm{Au}^{3+}$ to $\mathrm{Au}^{0}$. XRD analysis showed four distinct diffraction peaks in the $2 \theta$ range of $10^{\circ}-90^{\circ}$ at $38.14^{\circ}, 44.26^{\circ}, 64.54^{\circ}$, and $77.51^{\circ}$, respectively, which indexed the planes (111), (200), (220), and (311) of the cubic-face-centered gold. This was followed by a low peak at $81.74^{\circ}$, which was indexed as a (222) plane. The cubic-face-centered structures of gold matched those in the database of the Joint Committee on Powder Diffraction Standards, USA (JCPDS no. 00-004-0784), confirming that

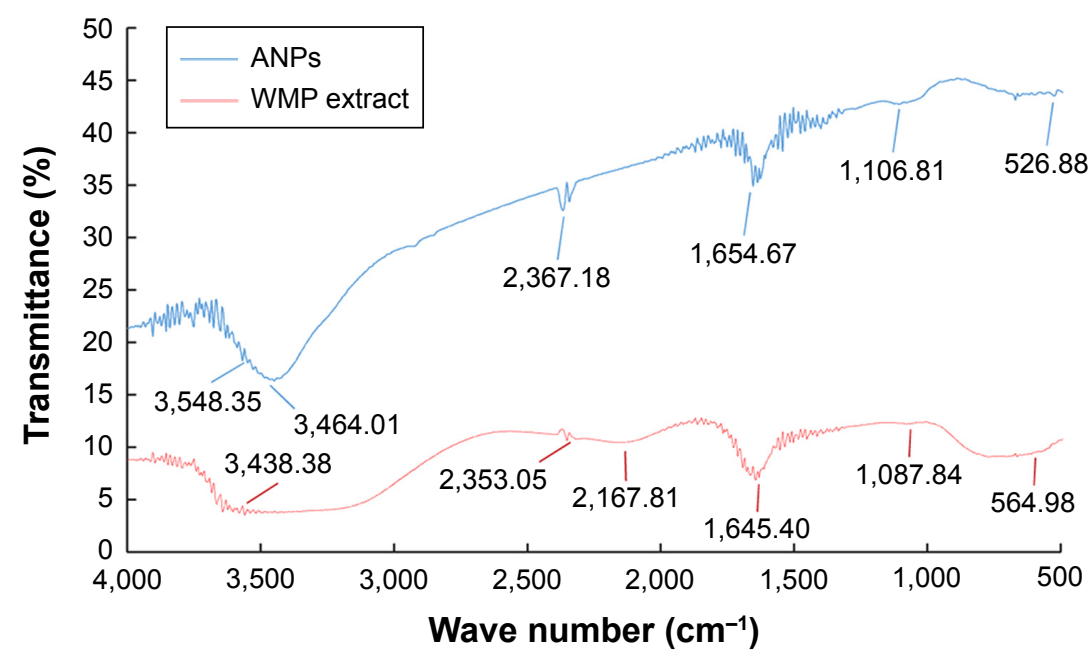

Figure 2 FT-IR analysis of gold nanoparticles (ANPs) synthesized using the aqueous extract of watermelon rind. Abbreviations: FT-IR, Fourier-transform infrared spectroscopy; WMP, watermelon outer peel. 

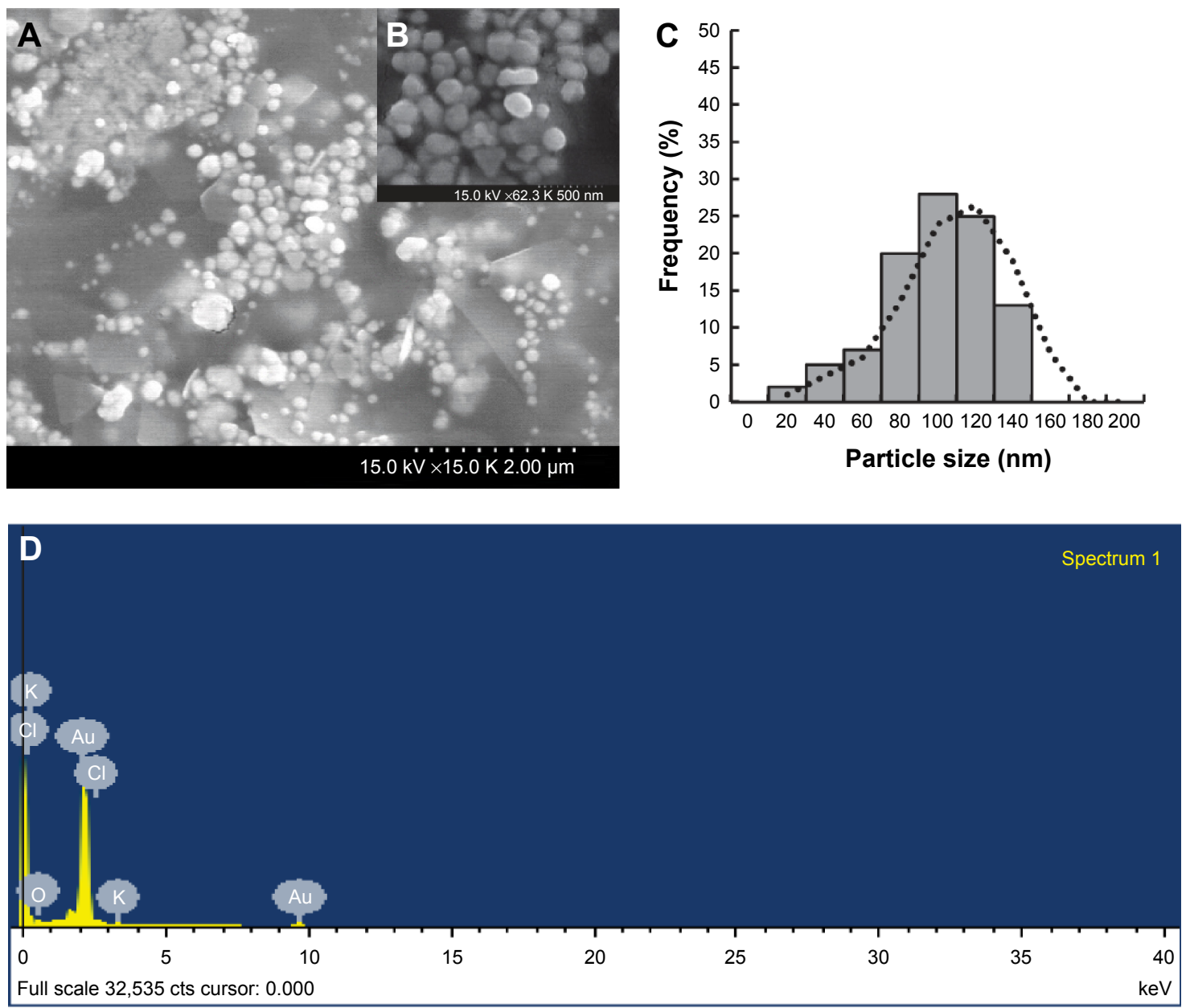

Figure 3 SEM, EDX analysis, and size distribution of gold nanoparticles (ANPs).

Notes: (A and B) SEM images; (C) size distribution of ANPs; (D) EDX spectra of gold nanoparticles.

Abbreviations: EDX, energy-dispersive X-ray; SEM, scanning electron microscopy.

the synthesized ANPs are composed of pure crystalline gold particles. These findings are further supported by similar results reported in other studies of ANPs. ${ }^{5,31,46}$ The TGA spectrum of the ANPs showed significant weight loss of ANPs when heated from $20^{\circ} \mathrm{C}$ to $700^{\circ} \mathrm{C}$ (Figure 5), indicating

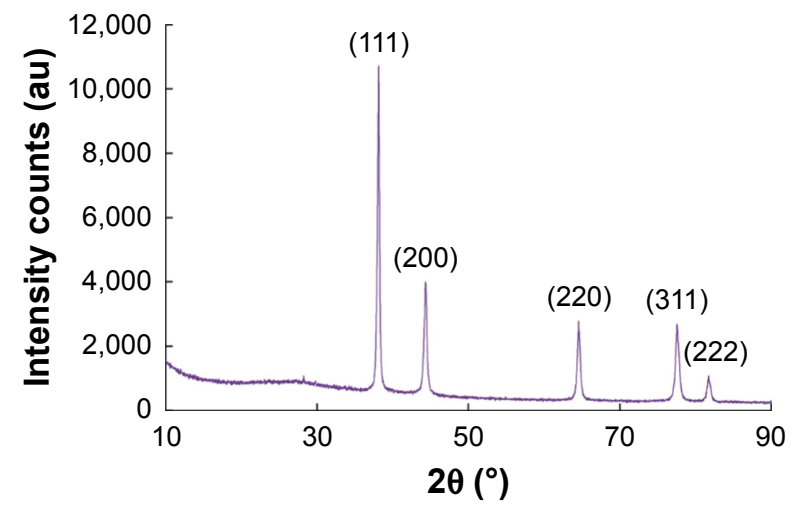

Figure 4 XRD spectra of gold nanoparticles. Abbreviation: XRD, X-ray powder diffraction. that, at higher temperature, the organic compounds from WAQ surrounding the ANPs, which acted as the capping agent for ANPs, were completely degraded. ${ }^{31}$

\section{Biopotential of ANPs}

The synthesized ANPs were evaluated for their potential antibacterial, synergistic, antioxidant, and proteasome inhibitory activity to predict their applicability in various fields such as the biomedical, pharmaceutical, and cosmetics industries.

\section{Determination of proteasome inhibitory potential of ANPs}

The proteasomes are responsible for the degradation of different types of cytoplasmic proteins (cyclins, misfolded proteins) and transcription factors. ${ }^{54}$ The human cancer cells possess an elevated level of proteasome activity, and inhibition of proteasome by the ANPs could be a novel approach for treatment of cancer. The proteasome inhibitors can also 


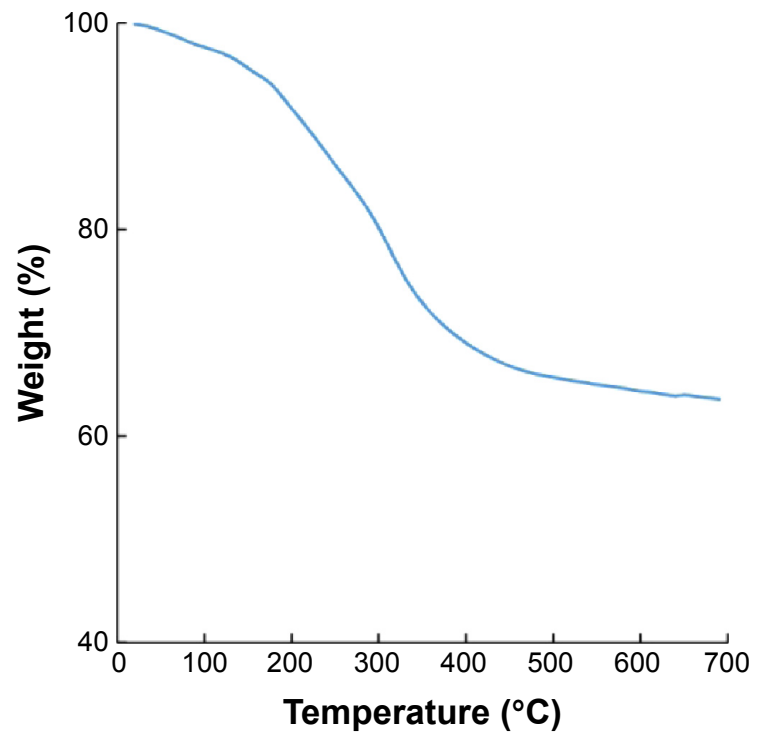

Figure 5 TGA analysis of gold nanoparticles.

Abbreviation: TGA, thermogravimetric analysis.

overcome various types of drug resistance in the cancer cells, ${ }^{55,56}$ thus in this investigation, the proteasome inhibitory potential of ANPs was investigated. The proteasome inhibitory potential of ANPs is presented in Figure 6. The results showed that ANPs at a concentration of $100 \mu \mathrm{g} / \mathrm{mL}$ and $10 \mu \mathrm{g} / \mathrm{mL}$ exhibited $28.16 \%$ and $19.33 \%$ proteasome inhibitory activity, respectively, whereas epoxomicin at a concentration of $5.56 \mu \mathrm{g} / \mathrm{mL}$ and $0.56 \mu \mathrm{g} / \mathrm{mL}$ exhibited $40.06 \%$ and $30.27 \%$ proteasome inhibitory activity, respectively. These results confirmed that the anti-proteasome potential of ANPs increased with higher concentrations of ANPs. Watermelon rind is citrulline-rich compound, which might have acted as the capping agent in the ANPs and been responsible for the proteasome inhibitory potential of ANPs ${ }^{50,53}$ The proteasome inhibitory potential of PEGylated PLGA nanoparticles with controlled and targeted drug delivery has been reported for the selective inhibition of proteasome-mediated homeostatic processes (proteostasis) in the lung epithelia. ${ }^{57}$ Similarly,

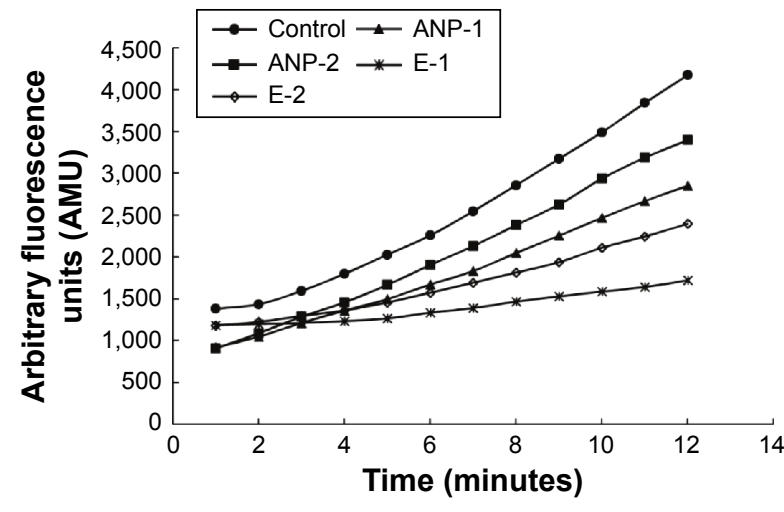

Figure 6 Proteasome inhibitory potential of gold nanoparticles and standard reference compound epoxomicin (E). ANP-I:100 $\mu \mathrm{g} / \mathrm{mL}$; ANP-2: $10 \mu \mathrm{g} / \mathrm{mL}$; E-I: $5.56 \mu \mathrm{g} / \mathrm{mL}$; and E-2: $0.56 \mu \mathrm{g} / \mathrm{mL}$.

Abbreviation: ANPs, gold nanoparticles.

nano-sized neodymium oxides were reported to possess proteasome inhibitory activity ${ }^{58}$ It is a well-known fact that the cell cycle check points and the DNA repair control mechanisms are defective in the cancer cells, and if these cancer cells are placed under stress condition by using proteasome inhibitors like the ANPs, then these cancer cells might not be able to correct the cell cycle transition blockade and could go into the apoptosis phase without affecting the normal cell. ${ }^{55}$ It is evident from the result that when different types of anticancer drugs are conjugated with the ANPs, it could exhibit significantly higher anticancer potentials without affecting the normal cells of the human body. Thus, ANPs could be potential candidates for targeted drug delivery and use in development of drugs related to selective inhibition of proteasome-mediated homeostatic processes.

\section{Determination of antibacterial activity}

The antibacterial potential of the ANPs was evaluated against five different foodborne pathogens: B. cereus ATCC 13061, E. coli ATCC 43890, L. monocytogenes ATCC 19115, S. aureus ATCC 49444, and S. typhimurium ATCC 43174. The results are presented in Table 1 and Figure 7. At $50 \mu \mathrm{g} / \mathrm{disc}$,

Table I Antibacterial activity of colloidal ANPs and standard antibiotics (kanamycin and rifampicin) against foodborne bacteria

\begin{tabular}{|c|c|c|c|c|c|c|c|}
\hline \multirow[t]{2}{*}{ Foodborne pathogens } & \multirow{2}{*}{$\begin{array}{l}\text { ANPs } \\
\text { (50 } \mu \text { g/disc) }\end{array}$} & \multirow{2}{*}{$\begin{array}{l}\text { WAQ extract } \\
(50 \mu \mathrm{g} / \text { disc })\end{array}$} & \multicolumn{2}{|c|}{ Positive control } & \multirow{2}{*}{$\begin{array}{l}\text { Negative } \\
\text { control* }\end{array}$} & \multirow[t]{2}{*}{ MIC $(\mu \mathrm{g} / \mathrm{mL})$} & \multirow[t]{2}{*}{ MBC $(\mu \mathrm{g} / \mathrm{mL})$} \\
\hline & & & $\begin{array}{l}\text { Kanamycin } \\
(5 \mu g / d i s c)\end{array}$ & $\begin{array}{l}\text { Rifampicin } \\
(5 \mu \text { g/disc) }\end{array}$ & & & \\
\hline Bacillus cereus ATCC I306| & $11.58 \pm 0.65^{\mathrm{a}, \#}$ & 0 & 0 & 0 & 0 & 50 & 100 \\
\hline Escherichia coli ATCC 43890 & $9.23 \pm 0.40^{b}$ & 0 & 0 & 0 & 0 & 50 & 50 \\
\hline Listeria monocytogenes ATCC 19115 & $0 \pm 0^{c}$ & 0 & 0 & 0 & 0 & - & - \\
\hline Staphylococcus aureus ATCC 49444 & $0 \pm 0^{c}$ & 0 & 0 & 0 & 0 & - & - \\
\hline Salmonella typhimurium ATCC 43174 & $11.15 \pm 0.35^{\mathrm{a}}$ & 0 & 0 & 0 & 0 & 50 & 100 \\
\hline
\end{tabular}

Notes: Values with different superscript letters in each column are significantly different at $P<0.05$. "Data are expressed as the mean zone of inhibition in $\mathrm{mm} \pm \mathrm{SD}$. $* 5 \% \mathrm{DMSO}$ Abbreviations: ANPs, gold nanoparticles; MBC, minimum bactericidal concentration; MIC, minimum inhibitory concentration; WAQ, watermelon aqueous extract; ATCC, American Type Culture Collection; DMSO, dimethyl sulfoxide; SD, standard deviation. 


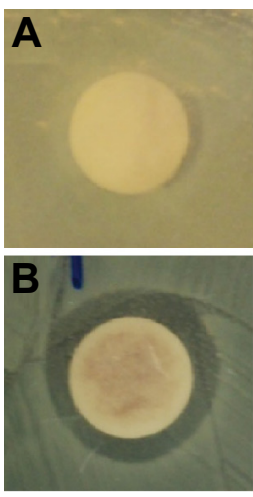

B. cereus

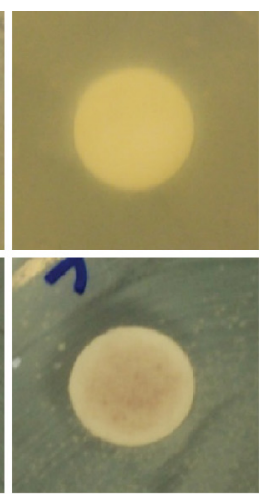

E. coli

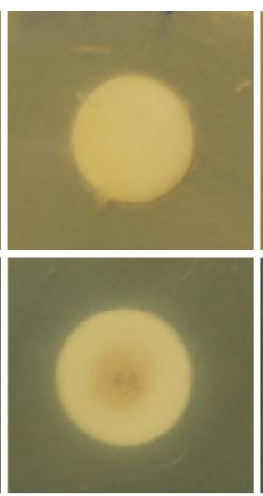

L. monocytogenes

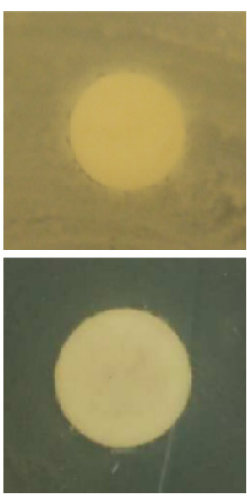

S. aureus

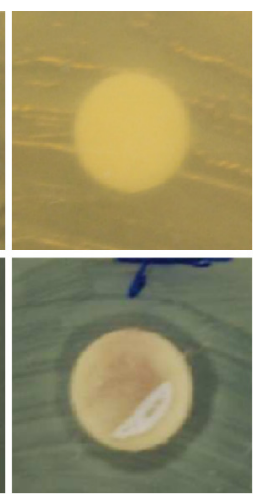

S. typhimurium

Figure 7 Antibacterial potential of (A) aqueous extract of watermelon rind and (B) gold nanoparticles.

Abbreviations: B. cereus, Bacillus cereus; E. coli, Escherichia coli; L. monocytogenes, Listeria monocytogenes; S. aureus, Staphylococcus aureus; S. typhimurium, Salmonella typhimurium.

the ANPs were active against B. cereus ATCC 13061 (11.58 mm inhibition zone), E. coli ATCC 43890 ( $9.23 \mathrm{~mm}$ inhibition zone), and S. typhimurium ATCC 43174 (11.15 inhibition zone), but inactive against $L$. monocytogenes ATCC 19115 and S. aureus ATCC 49444. The standard reference antibiotics at a concentration of $5 \mu \mathrm{g} / \mathrm{disc}$ and WAQ extract at $50 \mu \mathrm{g} /$ disc showed no inhibitory effects against any of the tested pathogens. The MIC and MBC values of ANPs ranged from 50 to $100 \mu \mathrm{g} / \mathrm{mL}$ (Table 1). The antibacterial activity of ANPs synthesized using biological sources was also previously reported. ${ }^{5,31}$ The antibacterial activity of different types of nanoparticles has been studied largely with different pathogenic bacteria during recent years. ${ }^{22,59,60}$ The bactericidal activity of the nanoparticles and their interaction with the pathogens has been previously reported. ${ }^{22,61}$ Due to the small size of the nanoparticles, they might be able to enter the bacterial cell membrane through bacterial porins and eventually cause cell death. The ANPs act against both the Gram-positive and Gram-negative foodborne bacteria and can thus find the application in food industries for preservation and packaging.

The synergistic antibacterial activities of ANPs mixed with two antibiotics (kanamycin and rifampicin) were further investigated, and the results are presented in Table 2 and Figure 8 . The mixture of ANPs $(25 \mu \mathrm{g})$ with kanamycin or rifampicin $(5 \mu \mathrm{g})$ exhibited significantly higher antibacterial activity than ANPs alone. Combined treatment with ANPs and kanamycin resulted in inhibition zones of 11.93-21.08 $\mathrm{mm}$ (Table 2), whereas treatment with ANPs combined with rifampicin generated inhibition zones ranging from 10.32 to $24.84 \mathrm{~mm}$ against all the five tested foodborne bacteria. Earlier reports suggested that the efficacy of the antibacterial activity of ANPs can be increased by addition of antibiotics, ${ }^{62,63}$ which was also demonstrated in this investigation. ANPs alone exhibited little or no activity against the five tested foodborne bacteria; however, when mixed with low concentrations of kanamycin and rifampicin, they displayed high inhibition potential against all foodborne bacteria (Table 2). There have also been reports of increased antibacterial activity of different antibiotics supplied with ANPs. ${ }^{64-66}$

The antibacterial mechanism of action of the ANPs combined with antibiotics against the pathogenic bacteria has been proposed that gold particles might have easily penetrated into the cell wall due to their smaller sizes, resulting in leakage of cellular material leading to cell death. ${ }^{67}$ It is also possible that the ANPs might have bound to the DNA of bacteria and have inhibited the uncoiling and transcription of DNA, leading to cell death. ${ }^{67}$ The antibacterial activity of ANP against the five foodborne bacteria might be due to these underlying mechanisms. Thus, ANPs with potent antibacterial potential could be used in various biomedical

Table 2 Synergistic antibacterial potential of colloidal ANPs against foodborne bacteria

\begin{tabular}{lll}
\hline $\begin{array}{l}\text { Foodborne } \\
\text { pathogens }\end{array}$ & $\begin{array}{l}\text { ANPs }+ \\
\text { kanamycin }^{\#}\end{array}$ & $\begin{array}{l}\text { ANPs }+ \\
\text { rifampicin }^{\#}\end{array}$ \\
\hline $\begin{array}{l}\text { Bacillus cereus ATCC } \\
\text { I306I }\end{array}$ & $11.93 \pm 0.42^{\mathrm{d}, *}$ & $12.01 \pm 0.40^{\mathrm{d}}$ \\
$\begin{array}{l}\text { Escherichia coli ATCC } \\
43890\end{array}$ & $21.08 \pm 0.94^{\mathrm{b}}$ & $10.32 \pm 0.30^{\mathrm{d}}$ \\
$\begin{array}{l}\text { Listeria monocytogenes } \\
\text { ATCC 19II5 }\end{array}$ & $12.16 \pm 0.36^{\mathrm{c}}$ & $10.56 \pm 0.25^{\mathrm{d}}$ \\
$\begin{array}{l}\text { Staphylococcus aureus } \\
\text { ATCC 49444 }\end{array}$ & $12.04 \pm 0.23^{\mathrm{c}}$ & $24.84 \pm 1.86^{\mathrm{a}}$ \\
$\begin{array}{l}\text { Salmonella typhimurium } \\
\text { ATCC 43I74 }\end{array}$ & $12.74 \pm 0.70^{\mathrm{c}}$ & $12.00 \pm 0.40^{\mathrm{d}}$ \\
\hline
\end{tabular}

Notes: *Data are expressed as the mean zone of inhibition in $\mathrm{mm} \pm \mathrm{SD}$. Values with different superscript letters in each column are significantly different at $P<0.05$. ${ }^{\# A N P s}(25 \mu \mathrm{g})+$ kanamycin $(5 \mu \mathrm{g})$. ${ }^{\# N P s}(25 \mu \mathrm{g})+$ rifampicin $(5 \mu \mathrm{g})$.

Abbreviations: ANPs, gold nanoparticles; ATCC, American Type Culture Collection; $\mathrm{SD}$, standard deviation. 

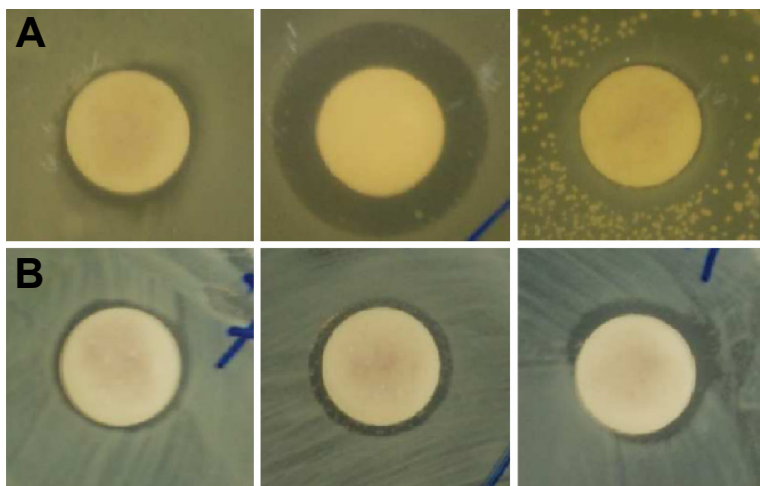

B. cereus

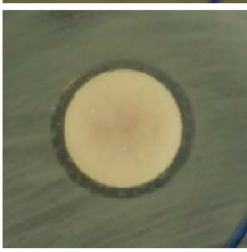

E. coli

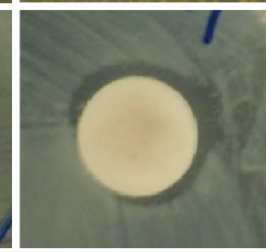

L. monocytogenes
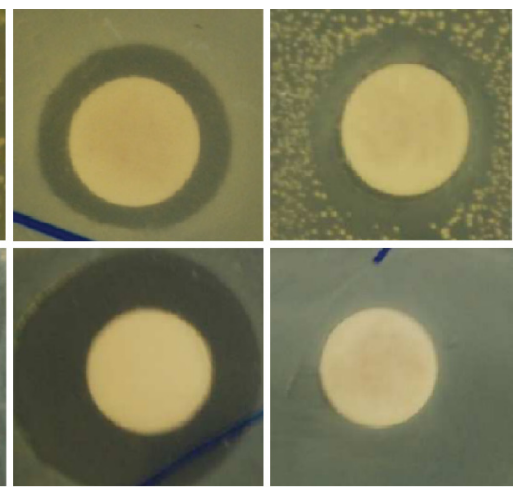

S. aureus

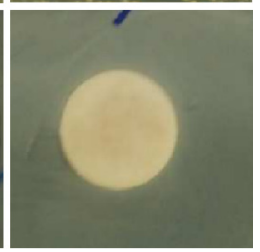

S. typhimurium

Figure 8 Synergistic antibacterial potential of gold nanoparticles with kanamycin (A) and rifampicin (B).

Abbreviations: B. cereus, Bacillus cereus; E. coli, Escherichia coli; L. monocytogenes, Listeria monocytogenes; S. aureus, Staphylococcus aureus; S. typhimurium, Salmonella typhimurium.

applications such as production of antibacterial cloth and fabric for wound dressing, as well as coating a wide variety of surfaces such as implants, antibacterial textiles, along with coating of instruments and utensils used by the medical and food sector industries. ${ }^{68}$

\section{Determination of antioxidant activity}

The antioxidant potential of ANPs was determined by various assays such as DPPH free radical scavenging, nitric oxide scavenging, ABTS radical scavenging assays, and the reducing power assay. The DPPH radical scavenging potential of ANPs is presented in Figure 9. The results showed a concentration-dependent manner of the potential of ANPs and BHT, the standard reference compound. Both ANPs and BHT displayed $24.69 \%$ and $36.96 \%$ scavenging activity at $100 \mu \mathrm{g} / \mathrm{mL}$, respectively. However, WAQ extract displayed very less activity of $6.17 \%$ at $100 \mu \mathrm{g} / \mathrm{mL}$ when compared with ANPs. The DPPH scavenging activity of ANPs might be attributed to their ability to donate electrons or hydrogen ions to DPPH free radicals to neutralize them. ${ }^{69}$ Moreover, the potential effect of ANPs might be due to their inhibitory

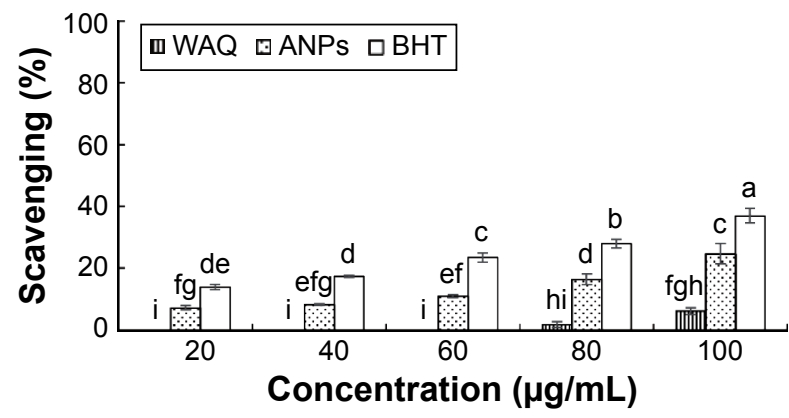

Figure 9 DPPH free radical scavenging potential of ANPs.

Note: Different superscript letters indicate significant differences in the mean at $P<0.05$.

Abbreviations: ANPs, gold nanoparticles; $\mathrm{BHT}$, butylated hydroxyl toluene; DPPH, I, I-diphenyl-2-picrylhydraxyl; WAQ, watermelon aqueous extract. effects on the peroxy radicals, which are the propagators of lipid peroxidation. ${ }^{70}$

The nitric oxide scavenging activity of ANPs is presented in Figure 10. ANPs possessed lower nitric oxide scavenging activity $(25.62 \%)$ than the reference compound BHT $(60.81 \%)$ at $100 \mu \mathrm{g} / \mathrm{mL}$. The WAQ extract displayed very low activity of $9.97 \%$ at $100 \mu \mathrm{g} / \mathrm{mL}$. Endogenously generated nitric oxide is a very unstable species involved in the regulation of many physiological processes. Additionally, this compound is associated with cancer and inflammatory diseases ${ }^{71}$ and even with aging of the skin. ${ }^{72}$ Thus, the nitric oxide scavenging effect of ANPs could make it a promising candidate for the cosmetic industry in the formulation of sunscreen cream lotions and anti-aging creams. ${ }^{73}$

As shown in Figure 11, ANPs displayed an ABTS activity of $29.42 \%$ at $100 \mu \mathrm{g} / \mathrm{mL}$, which was much lower than the activity of BHT $(96.02 \%$ at $100 \mu \mathrm{g} / \mathrm{mL})$. However, WAQ extract displayed significantly low activity of $3.6 \%$ at $100 \mu \mathrm{g} / \mathrm{mL}$. Many factors such as the stereoselectivity of the radicals, nature of the ANPs might have affected the potential of ANPs toward ABTS radicals. ${ }^{74}$ The reducing power

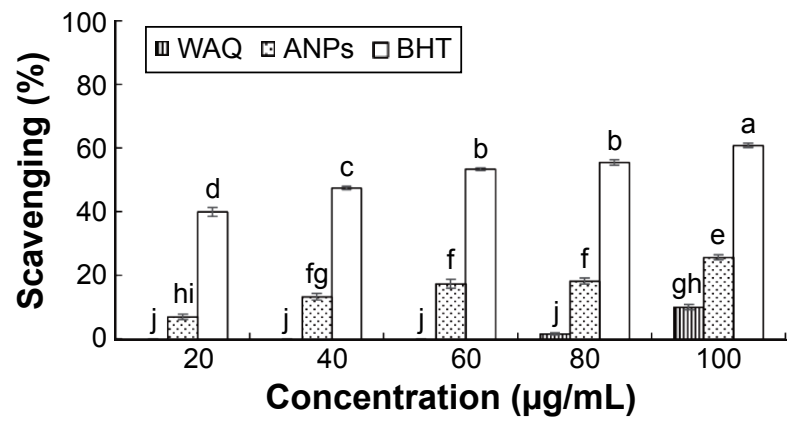

Figure 10 Nitric oxide scavenging potential of ANPs.

Note: Different superscript letters indicate significant differences in the mean at $P<0.05$.

Abbreviations: ANPs, gold nanoparticles; BHT, butylated hydroxyl toluene; WAQ, watermelon aqueous extract. 


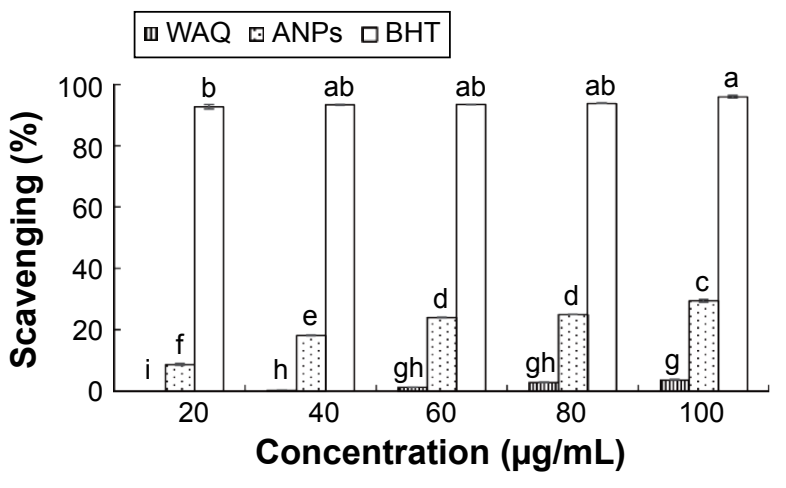

Figure I I ABTS radical scavenging potential of ANPs.

Note: Different superscript letters indicate significant differences in the mean at $P<0.05$.

Abbreviations: ABTS, 2,2'-azino-bis(3-ethylbenzothiazoline-6-sulphonic acid); ANPs, gold nanoparticles; BHT, butylated hydroxyl toluene; WAQ, watermelon aqueous extract.

of ANPs and BHT is presented in Figure 12. The results displayed strong reducing power of ANPs compared with BHT as evident from increased absorbance values in a concentration-dependent manner. The WAQ extract displayed very low activity of 0.099 absorbance value at $100 \mu \mathrm{g} / \mathrm{mL}$. Thus, the strong reducing power of ANPs confirms the antioxidant potential of ANPs. The antioxidant potential of ANPs synthesized using WAQ extract might be due to the presence of various types of phenolic compounds, vitamins, lycopene, and citrulline which are the major constituents of the watermelon rind, having acted as both reducing and capping agent for ANPs. ${ }^{29,51,52,75}$

\section{Conclusion}

In conclusion, this is, to the best of our knowledge, the first report of green synthesis of ANPs using the watermelon rind extract. The synthesized ANPs were characterized and confirmed by UV-vis spectroscopy and SEM image displayed its spherical shape, EDX confirmed they were primarily

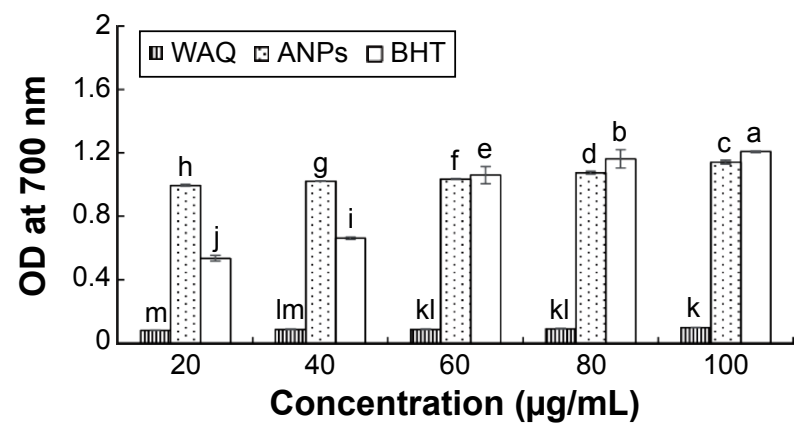

Figure 12 Reducing power potential of ANPs.

Note: Different superscript letters indicate significant differences in the mean at $P<0.05$.

Abbreviations: ANPs, gold nanoparticles; $\mathrm{BHT}$, butylated hydroxyl toluene; OD, optical density; WAQ, watermelon aqueous extract. composed of gold. The particle size distribution of the ANPs was in the range of 20-140 nm, with a broad size distribution. Furthermore, the presence of functional groups and the crystallite nature of the ANPs were confirmed by FT-IR and XRD analysis. The synthesized ANPs exhibited potential antibacterial activity against five foodborne pathogens and high synergistic activity when administered with the standard antibiotics kanamycin and rifampicin. ANPs also exhibited significant antioxidant and anti-proteasome inhibitory potential. The results presented herein describe a low-cost green synthesis method of ANPs from food waste materials that is environmentally benign and nontoxic in nature. Significant biopotentials of the synthesized ANPs could make them a potential candidate for application in the biomedical, pharmaceutical, cosmetic, food, and drug delivery fields.

\section{Acknowledgment}

This research was supported by the Systems and Synthetic Agro-biotech Center through the Next-Generation Bio-Green 21 Program (PJ011117012015), Rural Development Administration, Republic of Korea.

\section{Disclosure}

The authors report no conflicts of interest in this work.

\section{References}

1. Azam A, Ahmed AS, Oves M, Khan MS, Memic A. Size-dependent antimicrobial properties of $\mathrm{CuO}$ nanoparticles against Gram-positive and -negative bacterial strains. Int J Nanomed. 2012;7:3527-3535.

2. Oves M, Khan MS, Zaidi A, et al. Antibacterial and cytotoxic efficacy of extracellular silver nanoparticles biofabricated from chromium reducing novel os 4 strain of Stenotrophomonas maltophilia. PLoS One. 2013;8:e59140.

3. Sau TK, Rogach AL. Nonspherical noble metal nanoparticles: colloid-chemical synthesis and morphology control. Adv Mater. 2010;22:1781-1804.

4. Vilchis-Nestor AR, Sanchez-Mendieta V, Camacho-Lopez MA, Gomez-Espinosa RM, Arenas-Alatorre JA. Solventless synthesis and optical properties of $\mathrm{Au}$ and $\mathrm{Ag}$ nanoparticles using Camellia sinensis extract. Mater Lett. 2008;62:3103-3105.

5. Prakash P, Gnanaprakasam P, Emmanuel R, Arokiyaraj S, Saravanan M. Green synthesis of silver nanoparticles from leaf extract of Mimusops elengi, Linn. for enhanced antibacterial activity against multi drug resistant clinical isolates. Colloid Surf B. 2013;108:255-259.

6. Alivisatos P. The use of nanocrystals in biological detection. Nat Biotechnol. 2004;22:47-52.

7. Salata OJ. Applications of nanoparticles in biology and medicine. J Nanobiotechnol. 2004;2:3. doi:10.1186/1477-3155-2-3.

8. Lakshmipathy R, Palakshi Reddy B, Sarada NC, Chidambaram K, Khadeer Pasha SK. Watermelon rind-mediated green synthesis of noble palladium nanoparticles: catalytic application. Appl Nanosci. 2015;5: 223-228.

9. Bhattacharya D, Gupta R. Nanotechnology and potential of microorganisms. Crit Rev Biotechnol. 2005;25:199-204.

10. Mohanpuria P, Rana NK, Yadav SK. Biosynthesis of nanoparticles: technological concepts and future applications. J Nanopart Res. 2008; 10:507-517. 
11. Murawala P, Phadnis SM, Bhonde RR, Prasad BLV. In situ synthesis of water dispersible bovine serum albumin capped gold and silver nanoparticles and their cytocompatibility studies. Colloid Surf B. 2009;73:224-228.

12. Wang Y, He X, Wang K, Zhang X, Tan W. Barbated Skullcup herb extract-mediated biosynthesis of gold nanoparticles and its primary application in electrochemistry. Colloid Surf B. 2009;73:75-79.

13. Chulz-Dobrick M, Sarathy KV, Jansen M. Surfactant-free synthesis and functionalization of gold nanoparticles. J Am Chem Soc. 2005; 127:12816-12817.

14. Leonard K, Ahmmad B, Okamura H, Kurawaki J. In situ green synthesis of biocompatible ginseng capped gold nanoparticles with remarkable stability. Colloid Surf B. 2011;82:391-396.

15. Datar RH, Richard JC. Nanomedicine: concepts, status and the future. Med Innov Bus. 2010;2:6-17.

16. Vashir JK, Reddy MK, Labhasetwar VV. Nanosystems in drug targeting: opportunities and challenges. Curr Nanosci. 2005;1:47-64.

17. Kannan R, Rahing V, Cutler C, et al. Nanocompatible chemistry toward fabrication of target-specific gold nanoparticles. J Am Chem Soc. 2006;128:11342-11343.

18. Wangoo N, Bhasin KK, Mehta SK, Suri CR. Synthesis and capping of water-dispersed gold nanoparticles by an amino acid: bioconjugation and binding studies. J Colloids Interface Sci. 2008;323:247-254.

19. Justin Packia Jacob S, Finub JS, Narayanan A. Synthesis of silver nanoparticles using Piper longum leaf extracts and its cytotoxic activity against Hep-2 cell line. Colloid Surf B. 2012;91:212-214.

20. Bankar A, Joshi B, Kumar AR, Zinjarde S. Banana peel extract mediated novel route for the synthesis of palladium nanoparticles. Mater Lett. 2010;64:1951-1953.

21. Roopan SM, Bharathi A, Kumar R, Khanna VG, Prabhakarn A. Acaricidal, insecticidal, and larvicidal efficacy of aqueous extract of Annona squamosa L. peel as biomaterial for the reduction of palladium salts into nanoparticles. Colloid Surf B. 2012;92:209-212.

22. Azam A, Ahmed AS, Oves M, Khan MS, Habib SS, Memic A. Antimicrobial activity of metal oxide nanoparticles against Gram-positive and Gram-negative bacteria: a comparative study. Int J Nanomed. 2012;7:6003-6009.

23. Chen D, Ping Dou Q. The ubiquitin-proteasome system as a prospective molecular target for cancer treatment and prevention. Curr Protein Pept Sci. 2010;11:459-470.

24. Kisselev AF. Joining the army of proteasome inhibitors. Chem Biol. 2008;15:419-421.

25. Wu WK, Cho $\mathrm{CH}$, Lee $\mathrm{CW}$, et al. Proteasome inhibition: a new therapeutic strategy to cancer treatment. Cancer Lett. 2010;293:15-22.

26. Mort A, Zheng Y, Qiu F, Nimtz M, Bell-Eunice G. Structure of xylogalacturonan fragments from watermelon cell-wall pectin. Endopolygalacturonase can accommodate a xylosyl residue on the galacturonic acid just following the hydrolysis site. Carbohydr Res. 2008;343:1212-1221.

27. Quek SY, Chok NK, Swedlund P. The physicochemical properties of spray-dried watermelon powders. Chem Eng Process. 2007; 46:386-392.

28. Tlili I, Hdider C, Lenucci MS, Ilahy R, Jebari H, Dalessandro G. Bioactive compounds and antioxidant activities during fruit ripening of watermelon cultivars. J Food Comp Anal. 2011;24:923-928.

29. Naz A, Butt MS, Pasha I, Nawaz H. Antioxidant indices of watermelon juice and lycopene extract. Pakistan J Nutr. 2013;12:255-260.

30. Arriola NA, Dos-Santos GD, Prudencio ES, Vitali L, Petrus JCC, Amboni RDMC. Potential of nanofiltration for the concentration of bioactive compounds from watermelon juice. Int J Food Sci Technol. 2014;49:2052-2060.

31. Basavegowda N, Idhayadhulla A, Lee YR. Phyto-synthesis of gold nanoparticles using fruit extract of Hovenia dulcis and their biological activities. Ind Crops Prod. 2014;52:745-751.

32. Zhou Y, Itoh H, Uemura T, Naka K, Chujo Y. Preparation of $\pi$-conjugated polymer-protected gold nanoparticles in stable colloidal form. Chem Commun. 2001:613-614.
33. Diao WR, Hu QP, Feng SS, Li WQ, Xu JG. Chemical composition and antibacterial activity of the essential oil from green huajiao (Zanthoxylum schinifolium) against selected foodborne pathogens. J Agric Food Chem. 2013;61:6044-6049.

34. Kubo I, Fujita K, Kubo A, Nihei K, Ogura T. Antibacterial activity of coriander volatile compounds against Salmonella choleraesuis. J Agric Food Chem. 2004;52:3329-3332.

35. Naqvi SZH, Kiran U, Ali MI, et al. Combined efficacy of biologically synthesized silver nanoparticles and different antibiotics against multidrug-resistant bacteria. Int J Nanomed. 2013;8: 3187-3195.

36. Braca A, Tommasi ND, Bari LD, Pizza C, Politi M, Morelli I. Antioxidant principles from Bauhinia terapotensis. J Nat Prod. 2001; 64:892-895.

37. Makhija IK, Aswatha-Ram HN, Shreedhara CS, Vijay Kumar S, Devkar R. In vitro antioxidant studies of sitopaladi churna, a polyherbal ayurvedic formulation. Free Radic Antioxid. 2011;1:37-41.

38. Patra JK, Kim SH, Hwang H, Choi JW, Baek KH. Volatile compounds and antioxidant capacity of the bio-oil obtained by pyrolysis of Japanese red pine (Pinus Densiflora Siebold and Zucc.). Molecules. 2015;20:3986-4006.

39. Sun L, Zhang J, Lu X, Zhang L, Zhang Y. Evaluation to the antioxidant activity of total flavonoids extract from persimmon (Diospyros kaki L.) leaves. Food Chem Toxicol. 2011;49:2689-2696.

40. Mukherjee P, Senapati S, Mandal D, et al. Extracellular synthesis of gold nanoparticles by the fungus Fusarium oxysporum. Chem Bio Chem. 2002;3:461-463.

41. Mulvaney P. Surface plasmon spectroscopy of nanosized metal particles. Langmuir. 1996;12:788-800.

42. Sosa ME, Eppinger SD, Rowles CM. Identifying modular and integrative systems and their impact on design team interactions. J Mech Des. 2003;125:240-252.

43. Prathna TC, Chandrasekaran N, Raichur AM, Mukherjee A. Biomimetic synthesis of silver nanoparticles by Citrus limon (lemon) aqueous extract and theoretical prediction of particle size. Colloid Surf B. 2011;82:152-159.

44. Narayanan KB, Sakthivel N. Phytosynthesis of gold nanoparticles using leaf extract of Coleus amboinicus Lour. Mater Charact. 2010;61: 1232-1238.

45. Babu PJ, Sharma P, Kalita MC, Bora U. Green synthesis of biocompatible gold nanoparticles using Fagopyrum esculentum leaf extract. Front Mater Sci. 2011;5:379-387.

46. Coates J. Interpretation of infrared spectra. A practical approach. In: Meyers RA, editor. Encyclopedia of Analytical Chemistry. Chichester: John Wiley \& Sons Ltd; 2000:10815-10837.

47. Perkins-Veazie P, Collins JK. Flesh quality and lycopene stability of fresh-cut watermelon. Postharvest Biol Technol. 2004;31:159-166.

48. Parmar HS, Kar A. Protective role of Mangifera indica, Cucumis melo and Citrullus vulgaris peel extracts in chemically induced hypothyroidism. Chem Biol Interact. 2009;177:254-258.

49. Davis AR, Webber III CL, Fish WW, Wehner TC, King S, PerkinsVeazie P. L-citrulline levels in watermelon cultigens tested in two environments. Hortscience. 2011;46:1572-1575.

50. Al-Sayed HMA, Ahmed AR. Utilization of watermelon rinds and sharlyn melon peels as a natural source of dietary fiber and antioxidants in cake. Ann Agric Sci. 2013;58:83-95.

51. Campbell M. Extraction of Pectin from Watermelon Rind. [M.Sc. thesis]. Stillwater, OK: Graduate College of the Oklahoma State University; 2006:19-20.

52. Rahman B. Phytochemical Investigation of Citrullus canatus (Watermelon) Rind. [B. Pharm. thesis]. Dhaka: Department of Pharmacy, East West University; 2010.

53. Rimandoa AM, Perkins-Veazie PM. Determination of citrulline in watermelon rind. J Chromatogr A. 2005;1078:196-200.

54. Tanaka T, Nakatani T, Kamitani T. Inhibition of NEDD8-conjugation pathway by novel molecules: potential approaches to anticancer therapy. Mol Oncol. 2012;6:267-275. 
55. Almond JB, Cohen GM. The proteasome: a novel target for cancer chemotherapy. Leukemia. 2002;16:433-443.

56. Zhao J, Luque R, Qi W, et al. Facile surfactant-free synthesis and characterization of $\mathrm{Fe}_{3} \mathrm{O}_{4} @ 3$-aminophenol-formaldehyde core-shell magnetic microspheres. J Mater Chem A. 2015;3:519-524.

57. Vij N, Min T, Marasigan R, et al. Development of PEGylated PLGA nanoparticle for controlled and sustained drug delivery in cystic fibrosis. J Nanobiotechnol. 2010;8:22.

58. Chen Y, Yang L, Feng C, Wen LP. Nano neodymium oxide induces massive vacuolization and autophagic cell death in non-small cell lung cancer NCI-H460 cells. Biochem Biophys Res Commun. 2005;337:52-60.

59. Yoon KY, Byeon JH, Park JH, Hwang J. Susceptibility constants of Escherichia coli and Bacillus subtilis to silver and copper nanoparticles. Sci Total Environ. 2007;373:572-575.

60. Ruparelia JP, Chatterjee AK, Duttagupta SP, Mukherji S. Strain specificity in antimicrobial activity of silver and copper nanoparticles. Acta Biomater. 2008;4:707-716.

61. Raghupati KR, Koodali RT, Manna AC. Size-dependent bacterial growth inhibition and mechanism of antibacterial activity of zinc oxide nanoparticles. Langmuir. 2011;27:4020-4028.

62. Burygin GL. On the enhanced antibacterial activity of antibiotics mixed with gold nanoparticles. Nanoscale Res Lett. 2009;4:794-801.

63. Ravishankar Rai V, Bai AJ. Nanoparticles and their potential application as antimicrobials. In: Mendez-Vilas A editor. Science Against Microbial Pathogens: Communicating Current Research and Technological Advances. Badajoz, Spain: Formatex Research Center; 2011:197-209.

64. Gu H, Ho PL, Tong E, Wang L, Xu B. Presenting vancomycin on nanoparticles to enhance antimicrobial activities. Nano Lett. 2003;3: 1261-1263.

65. Grace NA, Pandian K. Antibacterial efficacy of aminoglycosidic antibiotics protected gold nanoparticles - a brief study. Colloids Surf A Physicochem Eng Asp. 2007;297:63-70.
66. Saha B. In vitro structural and functional evaluation of gold nanoparticles conjugated antibiotics. Nanoscale Res Lett. 2007;2:614-622.

67. Rai A, Prabhune A, Perry CC. Antibiotic mediated synthesis of gold nanoparticles with potent antimicrobial activity and their application in antimicrobial coatings. J Mater Chem. 2010;20:6789-6798.

68. Das SK. Gold nanoparticles: microbial synthesis and application in water hygiene management. Langmuir. 2009;25:8192-8199.

69. Rajamanikandan S, Sindhu T, Durgapriya D, Sophia D, Ragavendran P, Gopalkrishnan VK. Radical scavenging and antioxidant activity of ethanolic extract of Mollugo nudicaulis by in vitro assays. Indian J Pharma Educ Res. 2011;45:310-316.

70. Moraes MSA, Migliorini MV, Damasceno FC, et al. Qualitative analysis of bio oils of agricultural residues obtained through pyrolysis using comprehensive two dimensional gas chromatography with time-of-flight mass spectrometric detector. J Anal Appl Pyrol. 2012;98:51-64.

71. Cheng R, Glynn S, Santana WF, Switzer C, Ridnour L, Wink DA. Nitric oxide and redox inflammation in cancer. Adv Mol Toxicol. 2010;4:157-182.

72. Soneja A, Drews M, Malinski T. Role of nitric oxide, nitroxidative and oxidative stress in wound healing. Pharmacol Rep. 2005; 57:108-119.

73. Royer M, Prado M, Garcia-Perez ME, Diouf PN, Stevanovic T. Study of nutraceutical, nutricosmetics and cosmeceutical potentials of polyphenolic bark extracts from Canadian forest species. Pharm Nutr. 2013;1: $158-167$.

74. Abed NE, Kaabi B, Smaali MI, et al. Chemical composition, antioxidant and antimicrobial activities of Thymus capitata essential oil with its preservative effect against Listeria monocytogenes inoculated in minced beef meat. Evid Based Complement Alternat Med. 2014;2014:11.

75. Ang YK, Lam PY, Sia CM, Khoo HE, Yim HS. Comparison of antioxidant properties between red and yellow flesh watermelon rinds by different extraction conditions. Carpathian J Food Sci Technol. 2012;4: $52-62$.
International Journal of Nanomedicine

\section{Publish your work in this journal}

The International Journal of Nanomedicine is an international, peerreviewed journal focusing on the application of nanotechnology in diagnostics, therapeutics, and drug delivery systems throughout the biomedical field. This journal is indexed on PubMed Central, MedLine, CAS, SciSearch ${ }^{\circledR}$, Current Contents ${ }^{\circledR} /$ Clinical Medicine,

\section{Dovepress}

Journal Citation Reports/Science Edition, EMBase, Scopus and the Elsevier Bibliographic databases. The manuscript management system is completely online and includes a very quick and fair peer-review system, which is all easy to use. Visit http://www.dovepress.com/ testimonials.php to read real quotes from published authors. 